\title{
Discussion: An apparatus for the plastic limit and workability of soils
}

Graham Edward Barnes MSc, FICE, CGeol, FGS, MIHT Consultant in Geotechnical Engineering, Graham Barnes Consultancy, Manchester, UK

\section{Contribution by Brendan O'Kelly}

Barnes (2009) developed a novel apparatus that replicates the standard hand-rolling procedure in determining the plastic limit $\left(w_{\mathrm{P}}\right)$ state, as defined by Atterberg, with good reproducibility. Indicative stress and toughness values for the soil thread are measured with control of the strain rate during rolling out of the thread to a diameter of $3 \mathrm{~mm}$. The study also highlights the complex system of cyclic tension/compression, torsion and bending stresses induced during the rollingout procedure.

Referring to Figures 5 and 6 for the Lias Clay, the thread experiences fracture failure dry of $w_{\mathrm{P}}$, and is approximately elastic perfectly plastic just wet of $w_{\mathrm{p}}$. Pertinent plastic analyses are not readily available for the thread-rolling procedure, and it seems reasonable to apply a linear elastic analysis. Using the splitting cylinder (Brazil) analysis, the magnitudes of the principal stresses acting on an element centred on the thread axes are given by $\sigma=k P / L d$, where $k=-2 / \pi$ for the uniform tensile stress, $\sigma_{\mathrm{t}}$, induced over most of the vertical diametrical plane; $k=6 / \pi$ for the maximum compressive stress, $\sigma_{\mathrm{c}}$, on the transverse diameter; and $k \approx 0$ for the out-of-plane stress. From a Mohr's circle analysis, and with a principal stress ratio (compression to tension) of $3: 1$, the undrained splitting strength of the thread is given by $s_{\mathrm{ut}}=4 P / \pi L d$, with its value at $w_{\mathrm{P}}$ calculated for a diameter $d=3 \mathrm{~mm}$.

Indicative stress values for the Lias Clay thread plotted in Figures 5 and 6 have been calculated as simply $\sigma=P / L d$ (i.e. $k=1$ ), with $\sigma \cong 14.0$ for $d=3 \mathrm{~mm}$. Hence the undrained splitting strength of the thread, sut $\approx(4 / \pi)(14 \cdot 0)=17 \cdot 8 \mathrm{kPa}$; the mean stress is given by

$$
\sigma_{\mathrm{m}}=\left(\frac{6-2+0}{3}\right) \frac{P}{\pi L d}=5.9 \mathrm{kPa}
$$

and, following from the suggestion by Wood (1990), the mean effective stress $\sigma_{\mathrm{m}}^{\prime} \approx 2 \times 17.8=35.7 \mathrm{kPa}$ (i.e. about twice the remoulded undrained strength value at critical state), with the suction $u=\sigma_{\mathrm{m}}-\sigma_{\mathrm{m}}^{\prime}=29.7 \mathrm{kPa}$ for the Lias Clay thread at its $w_{\mathrm{P}}=30 \cdot 4 \%$. The soil remains at critical state, since the thread is being remoulded continuously. These calculated values are very low, and the actual undrained strength and suction values are
Brendan C. O’Kelly MEngSC, PhD, CEng

Department of Civil Engineering, Trinity College Dublin, Ireland almost certainly higher, since fine-grained soils are stiff to very stiff in consistency near $w_{\mathrm{P}}$, which would indicate significant shortcomings in the quasi-static splitting tension analysis. In particular, the effects of the torsion/bending stresses as well as cycling of the compound stresses and stress reversals that occur during the rolling out procedure are not considered, and, as noted by the author, soil is not linear elastic, as was assumed for the purposes of the splitting cylinder analysis. For the Lias clay, approximately 330 revolutions of the thread (115 clockwise and 115 counterclockwise) would have occurred during the 40-50 traverses required to reach the $w_{\mathrm{P}}$ state using the new apparatus (Figures 5 and 6).

It is also likely that the strength mobilised for the thread at $w_{\mathrm{P}}$ is different from the remoulded undrained shear strength value determined, for example, from unconfined compression tests on saturated specimens prepared at a moisture content equal to the $w_{\mathrm{P}}$ value, since the mechanism of failure for the soil thread can manifest itself differently, depending on the soil type, under the complex stress and deformation system during the rolling-out procedure. In the case of soils of high sand and silt contents, the author also found that some drying/drainage may occur during rolling out, leading to strain-hardening of the thread post-yield. In contrast, soils of high clay contents and of high activity effectively remained in an undrained condition, and under heavy remoulding during rolling out, frequently experienced strainsoftening to residual strength values.

It is also important to emphasise that the study clearly demonstrates that the plastic limit state, as defined by Atterberg, is governed by the soil toughness/workability. Indicative toughness values (work done/unit volume, calculated on the basis of a standard number of thread revolutions per traverse in reducing the thread from $6 \mathrm{~mm}$ to $4 \mathrm{~mm}$ in diameter) were determined by integrating the area under the stress-strain curves for the different soils tested using the new apparatus. Reasonable control of the strain rate was achieved during the rolling-out procedure and, by definition, the soil threads have the same ductility at $w_{\mathrm{p}}$. Hence the value of maximum toughness that is mobilised at $w_{\mathrm{p}}$ $\left(T_{\max }\right.$, Table 1) may be used with caution as an indirect indicator of the relative strength, bearing in mind that strain-softening/ hardening may be occurring during the rolling-out procedure. As expected, the $T_{\max }$ values for the different soils tested were found to vary over a wide range $\left(T_{\max }=7 \cdot 0-36.6 \mathrm{~kJ} / \mathrm{m}^{3}\right)$ : hence the 
strength at $w_{\mathrm{P}}$, as determined from the rolling-out procedure, also varies over a wide range.

In a more general context, and as reported by many researchers, including Wood (1990), the experimental results demonstrate that the ratio of the strength values measured at the extremities of the plastic range for fine-grained soils is not unique, since the $w_{\mathrm{P}}$ and liquid limit states are currently defined and determined by the limit of soil toughness and a standard undrained shear strength (fall-cone indentation method) respectively.

\section{Author's reply}

The split cylinder theory gives a measure of the stress applied for a linear elastic and static mode of failure. Others (Schofield and Wroth, Wood) have suggested that the formula for the stress applied to the soil thread in a plastic limit test can be obtained from this theory. The value of $k$ in the formula for stress (Equation 1 in the paper) is not known for the plastic limit test. I agree that for a static test the theoretical value of $k$ would be $4 / \pi$ $(\approx 1 \cdot 27)$. However, the soil thread is undergoing cycles of stress, and there must be a longitudinal or axial stress that promotes extrusion: so to adopt a specific value of $k$ in the stress formula would be introducing a theoretical element that, in the author's view, is not warranted. The stresses can only be considered indicative, and so a value of $k=1$ gives a simple form of equation. Also, this value is not too dissimilar to $4 / \pi$.

The author agrees that the static split cylinder theory has shortcomings in the determination of a stress value for the plastic limit test. The discusser's calculations for the splitting strength do not take account of the unknown axial stress applied to the thread due to the configuration of the top plate of the apparatus. In the plastic region of the stress-strain curve the soil may be at its critical state, but because of the rapid cycling of compression/ tension stresses, together with axial, bending and torsion stresses, the test is reflecting more of a fatigue strength, which tends to be smaller than the static strength.

As the discusser points out, there is also an unknown scale factor, comparing the strength in the plastic limit specimen to that of an unconfined compression test specimen. The plastic limit test specimen, at 3-6 mm diameter, is the smallest size in any test in soil mechanics. This size is most relevant when the soil is at the drier end near the plastic limit, when it is related to the size at which the micro/macrostructure of the soil becomes fractured/ aggregated, and when the soil thread crumbles.

The discusser notes that sand and silt contents affect the toughness values and the stress-strain behaviour during the test. The author is conducting further research into the effect of these particles, particularly particle interference and the overall size effect. The discusser also notes the strain-softening to near residual values that occurs with soils of high clay content and high activity. The author has found that, with these soils, more care is required with the load control, as strain-softening entails reducing the load applied; otherwise there is a risk of premature failure of the thread.

The discusser rightly emphasises that above the plastic limit the test is governed by the soil toughness/workability. From the toughness values a better understanding of soil behaviour between the plastic limit and the liquid limit is achieved; instead of previously being described as plastic, this range may now be seen to be in at least three regions: adhesive-plastic, soft-plastic and stiff-plastic.

The toughness values can be used to distinguish soils with different $T_{\max }$ values. This is particularly important in any process involving remoulding of a soil, such as in compaction in the civil engineering industry, in product forming in the ceramics industry and in soil preparation in the agricultural industry.

As the discusser points out, many researchers have found that the ratio of strength values at the plastic limit and the liquid limit is not unique. The liquid limit test is a strength-based test related to the fall cone theories. The plastic limit is not a strength-based phenomenon, but a demarcation between a ductile (or plastic) soil and a brittle soil. Professor Atkinson has recently published (Atkinson, 2010) some myths in soil mechanics. Perhaps the strength ratio between the plastic and liquid limit can now be consigned to the dustbin of mythology.

\section{REFERENCES}

Atkinson J (2010) Talking point. Ground Engineering 43(9): 7.

Barnes GE (2009) An apparatus for the plastic limit and workability of soils. Proceedings of the Institution of Civil

Engineers - Geotechnical Engineering 162(3): 175-185.

Wood DM (1990) Soil Behaviour and Critical State Soil

Mechanics. Cambridge University Press, Cambridge, UK.

\section{WHAT DO YOU THINK?}

To discuss this paper, please email up to 500 words to the editor at journals@ice.org.uk. Your contribution will be forwarded to the author(s) for a reply and, if considered appropriate by the editorial panel, will be published as a discussion in a future issue of the journal.

Proceedings journals rely entirely on contributions sent in by civil engineering professionals, academics and students. Papers should be $2000-5000$ words long (briefing papers should be 1000-2000 words long), with adequate illustrations and references. You can submit your paper online via www.icevirtuallibrary.com/content/journals, where you will also find detailed author guidelines. 